\title{
Comparison of Story Expressions and Symbolic Expressions of Sandplay Therapy between Korean Chinese Parents and Children both Separated and Living Together*
}

\author{
Kim, Yu Seon**
}

\begin{abstract}
$<$ Abstract $>$
The study was conducted in Yanbian, China, where we analyzed the differences in symbolic expressions during sandplay therapy between ethnic Korean children living with their parents and ethnic Korean children living apart from their parents. The researcher selected 10 children who were living with their parents and 10 children who were living apart from their parents for sandplay therapy. These children participated in eight sandplay sessions of 40 minutes duration over a period of three weeks. We classified the differences in symbolic expression into four different categories: use of figures, use of sand, use of space and process of sandplay. Although we did not set any specific themes, instead letting the children make their sand pictures as they wished, the two groups displayed different emotions toward their mothers and fathers. The participants also exhibited verbal and nonverbal differences as well as different attitudes toward sandplay therapy. These results demonstrate that sandplay therapy is an effective tool for therapeutic work with children in general who have problematic relationships with their parents.
\end{abstract}

Keywords : sandplay therapy, children living with their parents, children living apart from their parents, story expression, symbolic expression

* This paper is part of a 2017 master's thesis at Namseoul University

** Play therapist, Kindle Speech and Language Development Center (mssk55@naver.com) 
Journal of Symbols \& Sandplay Therapy, Vol.9 No.1.

\section{I . Introduction}

According to the Chinese-Korean population statistics, there are about 2.2 million Korean-Chinese residents living in China today (Ministry of Justice, 2015), constituting the largest Korea community outside the Korean peninsula. After the Korean government allowed working visit visas to overseas Koreans, the number of Korean-Chinese entering Korea surged, especially those from Yanbian (Kang, 2012; Koo, 2011). Statistic reports released by the Ministry of Justice indicate that the number of Chinese residents staying in Korea reached a record high of 640,000 , making them the biggest group of foreigners in Korea. The number Korean-Chinese has steadily increased from 590,000 in 2015 to 640,000 in 2016, and this phenomenon brought about significant changes to the traditional family unit of Korean-Chinese people in China. In other words, family disintegration has brought about compelling changes to the structure of Korea-Chinese families in recent years, resulting in the emergence of geese father families, grandparent families, single-parent families and separate families (Ahn, 2009).

The transfer of Korean-Chinese population to larger cities in China and also Korea and Japan became one of the causes of increased divorce rate, which consequentially led to increased number of adolescents who do not receive proper discipline at home. As a result, child education has also become a grave social problem within the Korean-Chinese community. The number of students from a broken family continues to grow in Yanbian Korean Autonomous Prefecture, accounting for nearly $54 \%$ of the entire student population. This means that one out of two students is from a broken home. The fact that this figure only continues to grow indicates the gravity of the situation (Kim, 2012).

Currently, the number of children and adolescents without a mother and/or a father due to parental divorce or employment activities is rising within the community of Korean-Chinese people. The Chinese Education Bureau reported that around $60 \%$ of the entire Korean-Chinese students experience the absence of a parent or parents (Park, 2008). In other words, one out of two students experience the absence of a father and/or a mother, and this figure is likely to grow in the future.

Because only a limited number of researches on Korean-Chinese families were conducted in China, this study mostly examined related researches conducted in Korea and 
noticed the following characteristics:

Among students from a separated family, $40 \%$ are from grandparent families, $20 \%$ are from single-parent families and another $20 \%$ live with relatives or foster parents. Moreover, $40 \%$ of the respondents said that they have been separated from their parents for five years or more, which was followed by $32 \%$ who reported less than three years; Majority of students from a separated home experienced a long-term separation of three years or more. When asked about the biggest difference between living with their parents and being separated from them, $40 \%$ answered that they "do not know what parental affection is" and $34 \%$ replied that they have "become introverted" in terms of their personality. As can be seen from their answers, many students who live apart from their parents are subject to negative experiences (Ahn, 2009).

Compared to non-separated children in the Korean-Chinese community, separated children are deprived of the normal parent-child interactions. Their guardians also usually fail to respond appropriately to their emotional changes. Therefore, these children can manifest emotional and behavioral problems such as introversion, timidity, vulnerability to emotions, disobedience, poor interpersonal relationships, impulsivity, neurosis, poor academic performance and strange habits (Lim, 2013). Continued school maladjustment behaviors may bring about developmental problems, which may then lead to social maladjustment problems during adulthood. Thus there is an increased social attention towards issues related to separated children.

Sandplay therapy is an effective therapy method for Korean-Chinese who experience difficulties in verbal expression, or any kind of expression for that matter. The sandpictures created by Korean-Chinese children who took part in this study include not only nonverbal but also unconscious contents, and hence will enable us to understand many of their stories that could not be communicated verbally.

In a space provided by the sand tray, sandplay therapist, a client creates a picture of his or her inner world using sand, water and figures, and therefore discover their genuine Self (Barbara, 2005). Dora Kalff combined Carl Jung's analytical psychology and Margaret Lowenfeld's World Technique, the latter of which was developed for children who have difficulties in verbal 
Journal of Symbols \& Sandplay Therapy, Vol.9 No.1.

expression, and termed the play "sandplay therapy" (Lee, 2003). Sandplay therapy is a pathway between consciousness and unconsciousness. Children use a sandtray, sand and figures to express their inner world via different themes, and therefore obtain a self-healing power.

Through sandplay therapy, clients express their experiences in both the inner world and outer world, hence revealing their unconscious. Sandplay therapy helps clients to become conscious of the aspects of themselves that were repressed.

In sandplay therapy, some clients talk about their creations with the therapist. By doing so, they come to understand the world they created inside the sandtray, recall past experiences that are connected to present difficulties and make associations, and consequentially identify various emotions such as joy, sorrow, pain and frustration. With the help of the therapist, clients grasp the key aspects of their stories, reflect on them, and gain a better understanding of themselves. Sandplay therapy put importance on not only images shown through the sandtray, but also clients' verbal narratives (Moon, 2002). By connecting the sandpictures with the client's verbal expressions, the therapist obtains more details of the client's unconscious (Park, 2011).

Kim and Yamanaka (2005) explained that symbols in sandplay therapy are personal, selective, literary and spiritual, and that they prompt the client's potential images from all physical aspects. Because clients generally do not plan the sandpictures they will create in advance, symbols play a therapeutic role even when clients observe figures from the shelf. Clients express their inner world through symbols, which trigger emotions and experiences. In other words, clients give life to symbols. By expressing themselves through symbols and their creations, clients come to recognize their inner potentials and are provided with a sense of safety. Consequentially, they can better express their inner problems and face them, which sometimes serve as an opportunity for inner healing.

Until now, there have been no studies that attempted to employ sandplay therapy for Korean-Chinese children from separated family and non-separated family. Hence this study sought to supplement the limitations of existing studies dealing with separated and non-separated children in the Korean-Chinese community. To this end, the research question is as follows: Are there any differences between Korean Chinese children from separated family 
and non-separated family in terms of their symbolic expression in sandplay therapy?

\section{П. RESEARCH METHOD}

\section{A. Participants}

The participants were comprised of twenty children living in living in Yanji. The research selected ten children who were not living with both parents but instead with a substitute caregiver (grandparent, aunt, uncle, etc.) and another ten children who were living with both parents and had never experienced separation.

B. Tools

This study used the sandplay therapy category checklist created by Jang (2017) to compare the differences in symbolic expression between the sandpictures of separated children and non-separated children. Table 1 is the checklist:

\section{Research Procedure}

A total of twenty children were provided with sandplay therapy for a period of around three weeks, from January 2 to 26 of 2017. Before conducting therapy, the researchers met with the children's parents or guardians for an intake.

The participants were informed that they would be given a total of 8 sandplay sessions, with each session lasting for 40 minutes. The therapy was performed in a quiet, private space that is free from disruptions from other people. A sandtray and various figures were placed in the room to allow the participants to feel free to express themselves and talk. There were two researchers, one of them being a trained sandplay therapist. With prior consent from all participants, all sessions were videotaped and recorded in writing. The participants agreed that the therapist bring a note, on which the participants' verbal and nonverbal 
Journal of Symbols \& Sandplay Therapy, Vol.9 No.1.

Table 1. Sandplay therapy category checklist

\begin{tabular}{|c|c|c|}
\hline \multirow{4}{*}{$\begin{array}{c}\text { (1) } \\
\text { Category } \\
\text { of } \\
\text { figures }\end{array}$} & People & Babies, children, adults, couples, families \\
\hline & Architecture & Buildings, houses, towers \\
\hline & Animals & $\begin{array}{l}\text { Land animals, sea animals, birds, wild animals, livestock, imaginary animals like } \\
\text { dragons, prehistoric extinct animals like dinosaurs }\end{array}$ \\
\hline & $\begin{array}{l}\text { Imaginary } \\
\text { and } \\
\text { archetypal } \\
\text { beings }\end{array}$ & $\begin{array}{l}\text { Imaginary animals(unicorn, Pegasus, dragon, horse), imaginary figures (wizard, } \\
\text { magician, fairy, witch, fairy tale and cartoon characters, hero), mythical beings } \\
\text { (Zeus, Hera, Grandmother Mago, Dangun, Ungnyo), humans (king, queen, } \\
\text { prince, princess, fairy, witch, wizard), shapes (square, mandala, cube, sphere, } \\
\text { circle, square, triangle, pyramid, sun, moon, star), valuable objects (marble, bead, } \\
\text { gold, treasure chest, crystal, glass object, precious minerals) }\end{array}$ \\
\hline \multicolumn{2}{|c|}{ Sandplay therapy process } & $\begin{array}{l}\text { During the course of sandplay therapy, the process of sandpicture creation was } \\
\text { observed and related items in the category checklist were ticked off. Plural } \\
\text { checking was allowed. }\end{array}$ \\
\hline \multicolumn{2}{|c|}{$\begin{array}{l}\text { (3) } \\
\text { Use of sand }\end{array}$} & $\begin{array}{l}\text { During the course of sandplay therapy, the use of sand was observed and related } \\
\text { items in the category checklist were ticked off. Plural checking was allowed. }\end{array}$ \\
\hline \multicolumn{2}{|c|}{$\begin{array}{c}(4) \\
\text { Use of sandtray space }\end{array}$} & $\begin{array}{l}\text { During the course of sandplay therapy, the use of space was observed and } \\
\text { related items in the category checklist were ticked off. Plural checking was } \\
\text { allowed. }\end{array}$ \\
\hline
\end{tabular}

expressions, behaviors, facial expressions were written down. After each session was over and the participants left the therapy room, photos of the sandpictures were taken. For those who did not wish to have their sessions videotaped, a summary was written on a note afterwards.

\section{Data Processing and Analysis}

A total of 158 sandpictures ( 78 created by separated children and 80 by non-separated children) were made during the research period by 20 research participants, 10 of whom are separated children and 10 non-separated children. By comparing the videos and photos taken during each therapy session, the symbolism was classified according to the types of figures, the sandplay therapy process, the use of sand and the use of sandtray space. When multiple symbols under the same category were used, they were counted as one. 
A frequency analysis was then done for each category $(\mathrm{t}=$ total number of sandtrays/number of symbolisms used) to examine the differences in symbolic expression between separated children and non-separated children from a Korean-Chinese family.

\section{RESEARCH RESULTS}

\section{A. Use of Figures}

\section{1) Humans}

The type of human figures that separated children used often were, in a descending order according to the frequency, "babies (16.6\%), "children" (15.3\%), "adults" (14.1\%), "families" (8.9\%) and "couples" (7.6\%). On the other hand, non-separated children used "adults (35.5\%), “couples" (25.0\%), "babies" (22.5\%), “families" (22.5\%) and “children" (21.2\%).

Non-separated children used more human figures than separated children did. The category which showed the greatest percentage difference was "couples" (17.4\%p).

Table 2. Difference in the use of human figures between separated children and non-separated children

\begin{tabular}{ccccc}
\hline & \multicolumn{2}{c}{ Separated children } & \multicolumn{2}{c}{ Non-separated children } \\
\hline Babies & 13 & $16.6 \%$ & 18 & $22.5 \%$ \\
\hline Children & 12 & $15.3 \%$ & 17 & $21.2 \%$ \\
\hline Adults & 11 & $14.1 \%$ & 28 & $35.0 \%$ \\
\hline Couples & 6 & $7.6 \%$ & 20 & $25.0 \%$ \\
\hline Families & 7 & $8.9 \%$ & 18 & $22.5 \%$ \\
\hline
\end{tabular}

\section{2) Architecture}

With regards to architecture figures, separated children used, in a descending order according to frequency, "houses" (26.9\%) and "towers" (6.4\%). Non-separated children also used "houses" $(52.5 \%)$ and "towers" (18.7\%). 
Journal of Symbols \& Sandplay Therapy, Vol.9 No.1.

Non-separated children used more architecture figures in comparison to separated children. The difference was especially greater in the case of house figures.

Table 3. Difference in the use of architecture figures between separated children and non-separated children

\begin{tabular}{ccccc}
\hline & \multicolumn{2}{c}{ Separated children } & \multicolumn{2}{c}{ Non-separated children } \\
\hline Houses & 21 & $28.9 \%$ & 42 & $52.5 \%$ \\
\hline Towers & 5 & $6.4 \%$ & 15 & $18.7 \%$ \\
\hline
\end{tabular}

\section{3) Animals}

With regards to animal figures that were used, separated children used, in a descending order according to the frequency, "wild animals" (38.4\%), "sea animals" (24.3\%), "extinct animals" (23.0\%), "livestock" (12.8\%), "land animals" (8.9\%) and "birds" (7.6\%). On the other hand, non-separated children used "sea animals" (17.5\%), "livestock" (17.5\%), "land animals" (15.5\%), "birds" (13.7\%), "wild animals" (10.0\%) and "extinct animals" (7.5\%).

Separated children used more "sea animals" ( ), "wild animals" (28.4\%p) and "extinct animals" (15.5\%p) than non-separated children did. The use of "wild animals" and "extinct animals" by separated children was especially high compared to non-separated children. On the other hand, non-separated children used more "land animals" (6.1\%p), "birds" (6.1\%p) and "livestock" (4.7\% ) than separated children.

Table 4. Difference in the use of animal figures between separated children and non-separated children

\begin{tabular}{ccccc}
\hline & \multicolumn{2}{c}{ Separated children } & \multicolumn{2}{c}{ Non-separated children } \\
\hline Land animals & 7 & $8.9 \%$ & 12 & $15.0 \%$ \\
\hline Sea animals & 19 & $24.3 \%$ & 14 & $17.5 \%$ \\
\hline Birds & 6 & $7.6 \%$ & 11 & $13.7 \%$ \\
\hline Wild animals & 30 & $38.4 \%$ & 8 & $10.0 \%$ \\
\hline Livestock & 10 & $12.8 \%$ & 14 & $17.5 \%$ \\
\hline Extinct animals & 18 & $23.0 \%$ & 6 & $7.5 \%$ \\
\hline
\end{tabular}




\section{4) Imaginary and archetypal beings}

With regard to imaginary and archetypal beings, separated children often used, in a descending order according to the frequency, was "imaginary figures" (32.0\%), "imaginary animals" (15.3\%), "mythical beings" (14.1\%), "humans" $(11.5 \%)$ and "objects" (10.2\%). In case of non-separated children, they often used valuable "objects" (27.5\%), "imaginary figures" (10.0\%), "imaginary animals" (7.5\%), "humans" (3.7\%) and "mythical beings" (2.5\%).

Separated children used more "imaginary animals" (7.8\%p), "imaginary figures" (22.0\%p), "mythical beings" (11.6\%p) and "humans" (7.8\%p) than non-separated children did. The use of "imaginary figures" and "mythical beings" by separated children was especially high compared to non-separated children. On the other hand, non-separated children used more “objects" (17.3\%p) than separated children did.

Table 5. Difference in the use of imaginary and archetypal figures between separated children and non-separated children

\begin{tabular}{ccccc}
\hline & \multicolumn{2}{c}{ Separated children } & \multicolumn{2}{c}{ Non-separated children } \\
\hline Imaginary animals & 12 & $15.3 \%$ & 6 & $7.5 \%$ \\
\hline Imaginary figures & 25 & $32.0 \%$ & 8 & $10.0 \%$ \\
\hline Mythical beings & 11 & $14.1 \%$ & 2 & $2.5 \%$ \\
\hline People & 9 & $11.5 \%$ & 3 & $3.7 \%$ \\
\hline Objects & 8 & $10.2 \%$ & 22 & $27.5 \%$ \\
\hline
\end{tabular}

\section{B. Sandplay Therapy Process}

Then the study observed the differences in how the two groups of children engaged in sandplay therapy. Separated children belonged to the following categories in a descending order: “changed figures frequently" (38.4\%), “immersed” (37.14\%), “prudent” (37.1\%), “often shifted the figures' location" (37.1\%), "unhesitant" (35.6\%), "hasty" (30.7\%), "often shifted their own location" (21.7\%), "continuously talked to the therapist" (19.2\%), “"ccreated an entirely new picture" (16.6\%), "excited" (15.3\%) and "fascinated" (15.3\%). In contrast, non-separated children were "immersed" (51.2\%), "hasty" (50.5\%), "unhesitant" (48.7), "fascinated" (47.5\%), 
Journal of Symbols \& Sandplay Therapy, Vol.9 No.1.

"prudent" (46.2\%), "excited" (31.2\%), "changed figures frequently" (22.5\%), "often shifted the figures' location" (18.7\%), "continuously talked to the therapist" (5.0\%), "often shifted their own location" (3.7\%) and "created an entirely new picture" (3.7\%).

The number of separated children who "changed figures frequently," "often shifted the figures' location," "often shifted their own location," "created an entirely new picture" and "continuously talked to the therapist" was higher than that of non-separated children. The difference was especially greater in case of changing the figures, figures' locations and their own locations. In contrast, the number of non-separated children who were "immersed," "fascinated" and "hasty" was higher than that of separated children. The difference was especially greater in case of "immersed" and "fascinated."

Table 6. Difference in the sandplay therapy process between separated children and non-separated children

\begin{tabular}{cllll}
\hline & \multicolumn{2}{c}{ Separated children } & \multicolumn{2}{c}{ Non-separated children } \\
\hline Prudent & 29 & $37.1 \%$ & 37 & $46.2 \%$ \\
\hline Immersed & 29 & $37.1 \%$ & 41 & $51.2 \%$ \\
\hline Excited & 12 & $15.3 \%$ & 25 & $31.2 \%$ \\
\hline Fascinated & 12 & $15.3 \%$ & 38 & $47.5 \%$ \\
\hline Hasty & 24 & $30.7 \%$ & 40 & $50.0 \%$ \\
\hline Unhesitant & 27 & $34.6 \%$ & 39 & $48.7 \%$ \\
\hline Changed figures frequently & 30 & $38.4 \%$ & 18 & $22.5 \%$ \\
\hline Often shifted the figures' location & 29 & $37.1 \%$ & 15 & $18.7 \%$ \\
\hline Often shifted their own location & 17 & $21.7 \%$ & 4 & $5.0 \%$ \\
\hline Created an entirely new picture & 13 & $16.6 \%$ & 4 & $5.0 \%$ \\
\hline Continuously talked to the therapist & 15 & $19.2 \%$ & 6 & $7.5 \%$ \\
\hline
\end{tabular}

C. Use of Sand

In terms of how the two group of children used sand, separated children manifested the following behaviors in a descending order: "mostly played with sand" (51.2\%), "dug up 
sand or buried figures inside" (48.7\%), "took out some or all of sand out of the tray" (25.6\%), "only placed figures on top of sand" (8.9\%) and were "unwilling to touch sand" (5.1\%). Non-separated children "only placed figures on top of sand" (45.0\%), "mostly played with sand" (36.2\%), "dug up sand or buried figures inside" $(25.0 \%)$, "took out some or all of sand out of the tray" (15.0\%) and were "unwilling to touch sand" (13.7\%).

There was a higher number of separated children for "mostly played with sand," "dug up sand or buried figures inside" and "took out some or all of sand out of the tray" than non-separated children. The difference was especially greater in case of "mostly played with sand" and "dug up sand or buried figures inside." However, there was a higher number of non-separated children for the categories of "unwilling to touch sand" and "only placed figures on top of sand" than separated children. The difference was especially greater in case of "only placed figures on top of sand."

Table 7. Difference in the use of sand between separated children and non-separated children

\begin{tabular}{ccccc}
\hline & \multicolumn{2}{c}{ Separated children } & \multicolumn{2}{c}{ Non-separated children } \\
\hline Unwilling to touch sand & 4 & $5.1 \%$ & 11 & $13.7 \%$ \\
\hline Mostly played with sand & 40 & $51.2 \%$ & 29 & $36.2 \%$ \\
\hline Dug up sand or buried figures inside & 38 & $48.7 \%$ & 20 & $25.0 \%$ \\
\hline Only placed figures on top of sand & 7 & $8.9 \%$ & 36 & $45.0 \%$ \\
\hline Took out some or all of sand out of the tray & 20 & $25.6 \%$ & 12 & $15.0 \%$ \\
\hline
\end{tabular}

\section{Use of Space}

The use of sandtray space for separated children was as follows in a descending order: "Noticeable empty space(s)" (46.1\%), “full” (29.4\%), “adequately used" (27.8\%), "sparse” (25.6\%), "too many figures" (25.6\%), "empty center" (19.2\%) and "figures outside the tray" (16.6\%). In the case of non-separated children, the percentages were: "Adequately used" (43.7\%), "full" (22.5\%), "too many figures" (18.7\%), "noticeable empty space(s)" (12.5\%), "sparse" (8.7\%), "figures outside the tray" (8.7\%) and "empty center" (6.2\%). 
Journal of Symbols \& Sandplay Therapy, Vol.9 No.1.

Table 8. Difference in the use of space between separated children and non-separated children

\begin{tabular}{ccccc}
\hline & \multicolumn{2}{c}{ Separated children } & \multicolumn{2}{c}{ Non-separated children } \\
\hline Full & 23 & $29.4 \%$ & 18 & $22.5 \%$ \\
\hline Sparse & 20 & $25.6 \%$ & 7 & $8.7 \%$ \\
\hline Noticeable empty space(s) & 36 & $46.1 \%$ & 10 & $12.5 \%$ \\
\hline Figures outside the tray & 13 & $16.6 \%$ & 7 & $8.7 \%$ \\
\hline Empty center & 15 & $19.2 \%$ & 5 & $6.2 \%$ \\
\hline Too many figures & 20 & $25.6 \%$ & 15 & $18.7 \%$ \\
\hline Adequately used & 22 & $27.8 \%$ & 35 & $43.7 \%$ \\
\hline
\end{tabular}

Compared to non-separated children, more number of separated children belonged to the following category: "Full," "sparse," "noticeable empty space(s)," "figures outside the tray," "empty center" and "too many figures." This was especially the case for "sparse," "noticeable empty space(s)" and "empty center." In contrast, there was a higher number of non-separated children in the category of "adequately used."

\section{DISCUSSION AND CONCLUSION}

The study aimed to provide sandplay therapy to Korean-Chinese children who are separated from their parents and those who live together with their parents, and therefore compared the differences in their symbolic expression. To this end, the study referred to verbatim notes and 158 sandpictures created by 10 separated children and 10 non-separated children.

After examining the verbatim notes and sandpictures, the symbolism was classified according to the types of figures, the sandplay therapy process, the use of sand and the use of sandtray space. When multiple symbols under the same category were used, they were counted as one.

Among "people" figures, separated children used babies and children more often than 
non-separated did, whereas non-separated children used adults, couple and families more often than separated children did. Human figures symbolize the client's past, present and future as well as people in their everyday reality. Child and baby figures used by separated children often appeared without the father, mother or an adult figure. In mythologies, the mother is the symbol of the Great Mother, the source, caregiver and guardian of all forms of life. It could therefore be interpreted that the presence of a caregiver and a guardian is absent in the lives of separated children. Sometimes, these children placed a warm nurturing figure in their sandtray to express their wish to be taken care of. Separated children who participated in this study were detached from their parents at a young age and therefore experienced feelings related to a loss, and were living with a third-party caregiver. And this experience led to express themselves as "babies" and "children" who still need care and nurturing. Some children, especially girls, regressed to their childhood years and provided that unfulfilled care and nurturing for themselves through therapy.

There was also a difference in how these two groups of children expressed their family. The verbatim notes say that separated children often mentioned their grandmothers and grandfathers when talking about their family whereas non-separated children often mentioned their mothers or fathers. The result showed that separated children consider not their parents, who are absent from home, but their grandparents as their "real family."

Among "architecture" figures, non-separated children used both houses and towers more often than separated children did, especially houses. The result seems attributable to the circumstance to which the child belonged. The house is a symbol of one's unconscious world, protection and shelter. Some of the separated children had to frequently change caregivers and in different houses as a result. These children thus may feel unprotected in life and it may be difficult for them to accept a house as a means of safety and protection. This may be an explanation of why the separated children used house figures less often than non-separated children did. There were also differences in the location and the ambience of the house. Separated children's house figures were placed in quiet and secluded areas, and these children described the houses as being lonely and isolated. In contrast, non-separated children's house figures were usually placed in a crowded neighborhood, and these children explained that 
Journal of Symbols \& Sandplay Therapy, Vol.9 No.1.

people living in the house have a good relationship with their neighbors.

Among "animal" figures, separated children used sea animals, wild animals and extinct animals often relative to non-separated children, whereas non-separated children used land animals, birds and livestock more frequently. Separated children predominantly used wild animals, while non-separated children predominantly used sea animals and livestock. Photos and verbatim notes showed that separated children often created scenes in which strong, aggressive animals are attacking weak animals. These children used strong animals to represent themselves; Strong animals represent instinctive energy and power. As far as siblings are concerned, nine out of ten non-separated children in this study were the only child in the family. However, most of the separated children, although they may have no biological siblings, often lived with their cousins. The verbatim notes suggest that in case of non-separated children, animals represent friends or other people who are close to them. It appeared children with no siblings and who spent little time with friends needed friends as companions.

Among "imaginary and archetypal beings," the figures that separated children used often relative to non-separated children were "imaginary animals," "imaginary figures," "mythical beings" and "humans." The sandpictures and verbatim notes of separated children showed that they often portray a story in which monsters with evil and destructive powers appear together with gods or a hero. Initially, the hero confronts the monsters and experiences trials. The hero would sometimes defeat the monster but would sometimes be killed by them. It appeared that separated children have ambiguous attitudes toward their parents: understanding why the parents had no choice but to leave them to earn money overseas, yet feeling abandoned by them. The hero figure, which represents the ambiguity, suggests that the children are either defeating the ambiguity or are killed by it. On the other hand, non-separated children frequently used figures belonging to the category of "valuable objects" like treasures and jewels. Kalff (1983) explained that jewels are a symbol of the genuine Self. Some of the non-separated children who used precious figures said that they are off to find treasures on a boat, which implies that they are embarking on a boat journey in discovery of their genuine Self.

As for the sandplay therapy process, a higher number of separated children belonged 
to the categories of "changed figures frequently," "often shifted the figures' location," "often shifted their own location," "created an entirely new picture," and "continuously talked to the therapist" whereas a higher number of non-separated children pertained to the categories of "immersed," "prudent," "unhesitant," "hasty," "excited" and "fascinated." As shown through the verbatim notes and the video clips, separated children often changed their choice of figures and also switched the location of the figures, which is closely linked to their anxiety. One child, after hesitating where to place the figures for a long time, repeatedly put figures in and out of the tray. Another child repeatedly changed the location of the figures or the location from where he or she created the picture. Most of these children had difficulties in making choices, and were unsure of their own decisions. There were also those who displayed discomfort about talking about themselves or to go into the depths of the unconscious. They also found talking about their emotions awkward or displeasing. There was also a child who, in the middle of making a sandpicture, stopped what he or she was doing and started all over again. Compared to non-separated children, most of the separated children took part in this research involuntarily, at the instructions of their caregivers. Hence most of them were disinterested in sandplay therapy at the beginning, and showed a low level of concentration. Some of these children were unable to choose figures from the shelf; there was even a child who verbally said, "I can't choose [figures]." However, as the therapy process reached near its end, an increasing number of separated children began to show interest in sandplay. One of the separated children kept on conversing with the therapist, asking questions or making requests such as, "What is this [figure]?" "Where should I place this to make it look pretty?" "Can you pick [the figures] for me?"

Many of the separated children living with a caregiver other than their parents lived with the children of that caregiver. These children were observed to be more sensitive about how the therapist might judge them. This is probably attributable to their being deprived of the opportunity to make their own decisions in life; they probably only followed the decisions made by their caregivers. Hence separated children were rather passive while engaging in sandplay. They behaved in a way which indicated that they found it important to select figures that please the therapist, and create beautiful-looking sandpictures that will bring out positive 
Journal of Symbols \& Sandplay Therapy, Vol.9 No.1.

responses. In contrast, non-separated children were prudent and also unhesitant in choosing their own figures. Boys especially were immersed in the play, showed excitement and interest, and choose figures without hesitation, while girls were especially prudent in selecting the figures. Many of these non-separated children participated in sandplay therapy out of their own will rather than being forced by parents, which means that they would more likely be engaged in the play and show interest.

As for use of sand, a higher number of separated children belonged to the categories of "mostly played with sand," "dug up sand or buried figures inside," "took out some or all of sand out of the tray," "only placed figures on top of sand" and "unwilling to touch sand," whereas a higher number of non-separated children belonged to the categories of "only placed figures on top of sand" and "unwilling to touch sand." Both separated and non-separated children used dry sand, but the sand was sometimes used in a very different way. Separated children used sand in a destructive way, i.e., they buried figures - often human figures inside sand. In addition, many of these children continue to touch sand while saying hello to the therapist or while taking about their creation. A child said that he or she enjoyed the cool, soft feeling of the sand. Among the separated children, some of them touched hand at a state of anxiety, without being able to meet eyes with the therapist. These were the children who were reluctant to talk about themselves, and they touched sand more than usual when talking about their family members. It seemed that these children felt a bit more relaxed by touching sand when talking.

As for the use of sandtray space, a more number of separated children belonged to the categories of "full," "sparse," "noticeable empty space(s)," "figures outside the tray," "empty center" and "too many figures." In contrast, a more number of non-separated children belonged to the category of "adequately used." Separated children would either use too many figures that would use up the entire sandtray space, or too little figures that would leave the center area or other areas of the noticeably empty.

This study confirmed that there is a difference in the symbolic expression between Korean-Chinese children who are separated from their parents and Korean-Chinese children who are not separated from their parents. Even though these children were not directed to depict a 
specific theme in their sandpictures and were given freedom to create whatever they want, there were differences in their emotions toward their family, mother and father; their verbal and nonverbal expressions, and their attitude toward sandplay therapy. These findings indicate that sandplay therapy provides a basic study for identifying the differences between these two children and for adequate therapeutic interventions.

\section{References}

An, B. (2009). The study about Korean-Chinese student separated from their parent according as supernational movement. Journal of Northeast Asian Studies, 14(3), 153-177

Jang, M. (2017). Analytical psychological sandplay therapy. Seoul: Hakjisa.

Kang, J. (2012). Diaspora and contemporary Yanbian Korean Chinese's imagined community: The Social Construction and Reterritorialization of the Ethnic Community. Korean Journal of Sociology, 46(4), 96-146

Kim, D. (2012). A study of the effect on the psychological adjustment of Korean Chinese adolescents whose parents are working abroad: Focused on the Yanbian Korean of China. Master's thesis, Soongsil University.

Kim, M. (2012). A study of factors influencing behavioral problems of Korean-Chinese children and Chinese children in Yanbian area. Korea Journal of Counseling, 13(3), 1141-1157.

Kim, Y. \& Yamanaka (2005). Essence of sandplay therapy. Seoul: Hakjisa

$\mathrm{Ku}, \mathrm{J}$. (2011). The migration of Koreans in the era of globalization and transnational social space: By the example of Qingdao, China. Han'guk Minjok Munhwa, 40(1), 421-457.

Lee, Y. (2003) Analytical psychological understanding of mythology: Three stages of mythology in terms of developmental processes of consciousness. The Journal of Aesthetics and Science of Art, 17, 207-239.

Lim, S. (2013). Effect of the happiness enhancement program on euphoria and adaptation to school life of children from broken families in Yanbian, China. Master's Thesis, Graduate School of Education, Jeju National University.

Ministry of Justice (2015). Current status of Koreans with foreign nationality, http://www.moj. 
Journal of Symbols \& Sandplay Therapy, Vol.9 No.1.

go.kr/HP/MOJ03/index.do

Moon, C. (2010). Sandbox story. Paju: Idam Books

Park, S. (2011). Comparison of the expression patterns according to the type of adult attachment and the stories shown in the sandplay therapy. Master's thesis, Namseoul University

Park, J. (2008). Influence from the change of family structure caused by manpower export on school life adjustment of the high school students. Master's thesis, Kyung Hee University 